\title{
Corrida no ciclo trigonométrico: uma animação para o aprendizado de arcos e ângulos
}

Michele Maciel Sacramento ${ }^{1}$

Andréa Cardoso ${ }^{2}$

José Carlos de Souza Júnior ${ }^{3}$

\author{
${ }^{1}$ Aluna Licencianda do curso de Matemática da Universidade Federal de Alfenas (UNIFAL-MG). Alfenas. MG. E-mail: \\ michele_macielsacramento@hotmail.com \\ ${ }^{2}$ Professora Adjunto III do Instituto de Ciências Exatas da Universidade Federal de Alfenas (UNIFAL-MG). Alfenas. \\ MG. - E-mail: andreac74@uol.com.br \\ ${ }^{3}$ Professor Adjunto IV do Instituto de Ciências Exatas da Universidade Federal de Alfenas (UNIFAL-MG). Alfenas. \\ MG. - E-mail: jose.souza@unifal-mg.edu.br
}

\section{Recebido em: 27/05/2013 - Aprovado em: 30/07/2013 - Disponibilizado em: 15/08/2013}

Resumo: Estudantes procuram cada vez mais, por recursos digitais como fonte de pesquisa e complemento a aulas presenciais. Entretanto há carência de material didático de qualidade, especificamente em relação à conceitos de matemática elementar. Descrevemos neste trabalho, a utilização do objeto de aprendizagem desenvolvido para motivação e estudo de arcos e ângulos no ciclo trigonométrico. O objeto de aprendizagem está em formato de animação digital e é parte integrante de videoaulas cujo objetivo é a aprendizagem de funções trigonométricas. O objeto de aprendizagem apresentou boa aceitação e promoveu o avanço no conhecimento sobre o ciclo trigonométrico e medidas de arcos e ângulos.

Palavras chave: Ensino de Matemática, Funções Trigonométricas, Material Didático, Objetos de Aprendizagem.

\begin{abstract}
Students are increasingly looking for digital resources as a source of research and complement for the presencial lessons. However there is a lack of teaching material of quality, specifically in relation to the concepts of elementary mathematics. In this paper, we describe the use of learning objects developed for motivation and study of arcs and angles in trigonometric cycle. The learning object is in the form of digital animation and is an integral part of video lessons aimed at learning of trigonometric functions. The learning object has presented good acceptance and promoted the advancement in knowledge about trigonometric cycle and measures of arcs and angles.
\end{abstract}

Keyword: Mathematics Teaching, Trigonometric Functions, Teaching Material, Learning Objects.

\section{INTRODUÇÃO}

\section{Os Parâmetros Curriculares Nacionais} (1998) recomendam que o ensino da Matemática deva gerar o desenvolvimento do pensamento crítico através da utilização de diferentes fontes de informação e recursos proporcionando aos discentes a capacidade de absorver e arquitetar seu conhecimento.

Entretanto, exames nacionais e avaliações internacionais revelam, especificamente em relação à matemática, que cada vez mais, os estudantes apresentam conhecimento limitado, pouca criatividade, senso crítico e deficiências em leitura, interpretação e resolução de problemas. A presente situação pode ser em parte o resultado de uma matemática escolar restrita ao trabalho mecânico com a utilização de fórmulas e uma grande quantidade de exercícios do tipo "calcule" sem preocupações com contextualização, 
resolução de problemas e com a compreensão dos conceitos. Segundo Lima (2001), os conceitos matemáticos estão sendo estudados em sala de aula mediante o apoio, praticamente exclusivo, de livros didáticos que apresentam sérios erros, como definições, raciocínios, métodos de resolução de problemas e respostas inteiramente inadequados e até desprovidos de significado. Assim, é urgente a complementação do livro didático através de recursos dinâmicos e interativos com potencial para motivar, induzir a descobertas e instruir.

Mediante esta recomendação e o desenvolvimento acelerado de uma sociedade altamente tecnológica, percebe-se que a tecnologia se tornou um forte aliado na estruturação das áreas sociais, científicas e educacionais.

A aplicação de tecnologias de informação e comunicação (TICs), no âmbito educacional, podem proporcionar estímulos, visualização, experimentação e a representação, levando a compreensão dos conceitos e também despertando o interesse e a curiosidade dos alunos frente a tópicos considerados, a princípio, difíceis e incompreensíveis. Assim, o aprender se torna, segundo Versuti (2004), um processo ativo e dinâmico, no qual, os atores organizam novas informações, utilizando o pensamento crítico e criativo.

Concordando com Bizelli (2009) quando afirma que os alunos já incorporam, ao seu processo de estudo, o uso de recursos da internet como complementação à aula presencial. Os recursos tecnológicos tornamse um instrumento de mediação entre o aluno e o conhecimento de acordo com os pressupostos da Teoria da Atividade de Engeström. Assim, na teoria da atividade segundo Engeström (1999), uma atividade é composta por três elementos: o sujeito, o objeto e as ferramentas de mediação entre o sujeito e este objeto que levam a uma melhor concretização do abstrato.

Neste trabalho, nos referimos a animação como um objeto de aprendizagem (OA). Atualmente estão disponíveis na internet, inúmeros recursos tecnológicos e AO's, em constante processo de modificação e atualização. Em particular quando se busca por recursos para o ensino de matemática, encontra-se grande quantidade de material defasado e com baixa qualidade de conteúdo, em sua maioria, com simplificação excessiva ou ausência de preocupação didática, além de gravações de aulas presenciais, com péssima resolução, e predominantemente em idioma estrangeiro.

Dentre os temas matemáticos existentes, escolheu-se o assunto funções como fonte de estudo por ser um dos pilares para o aprendizado de matemática superior. Entretanto, tal conhecimento não deve ser apenas justificado por estas instâncias. O conceito de função e funcionalidade não fica restrito apenas à própria matemática. As habilidades desenvolvidas com o estudo deste conteúdo podem auxiliar na construção de 
modelos para diversas situações da vida real, contribuindo assim, para a formação e inserção do cidadão na sociedade. Entre as funções trabalhadas, escolheu-se as funções trigonométricas, na qual, para sua compreensão é essencial o entendimento de conceitos prévios, como o ciclo trigonométrico.

\section{VIDEOAULAS}

Neste texto, entende-se por videoaulas uma animação multimídia, que possibilita apresentar conceitos dinamicamente através de textos e imagens, os quais são apresentados simultaneamente e não, sucessivamente, como ocorre em hipertextos. Este tipo de conteúdo digital é propício para ser utilizado como fonte educativa uma vez que, segundo Mayer (2001), os estudantes aprendem melhor com animações multimídia quando: combinam-se narração e imagens do que só com palavras. Assim, proporcionando uma fonte de pesquisa e aprendizagem para os alunos que desejam expandir o aprendizado oferecido em sala de aula e para aqueles discentes que possuem dificuldade em matemática, tentando sanar suas deficiências e aprimorar seu conhecimento.

O desenvolvimento das videoaulas originou-se de um projeto de pesquisa, com interface com a extensão universitária. A equipe de trabalho é composta por dois
Assim, o objetivo deste trabalho é investigar $\mathrm{o}$ impacto na motivação $\mathrm{e}$ consolidação de saberes por meio de uma animação denominada corrida no ciclo trigonométrico. O objetivo do OA é motivar e promover a identificação de arcos e ângulos no ciclo trigonométrico. A animação é parte complementar de videoaulas, para o ensino de funções trigonométricas.

professores pesquisadores e estudantes de licenciatura em matemática. $\mathrm{O}$ projeto visa produzir material didático digital sobre o tema funções.

As sequências didáticas adotadas nas videoaulas foram construídas abordando diferentes tipos de funções, como função afim, função quadrática e funções trigonométricas, possuindo suas atividades estruturadas de acordo com a Teoria da Atividade e no ciclo expansivo de Engeström (1999).

O ciclo expansivo, descrito nessa teoria, é composto por ações de aprendizado que promovem a ascensão do concreto para o abstrato. Estas ações são questionamento, análise, modelagem, avaliação da modelagem, implementação do modelo, reflexão e avaliação do processo e consolidação. Assim, de acordo com Cardoso (2011), o ciclo expansivo inicia-se com o sujeito questionando uma determinada prática, e expandindo gradativamente para o desenvolvimento de uma nova prática. 
Com a finalidade educacional e de motivação para a aprendizagem, algumas referências aos OA's foram inseridas nas videoaulas. Estes objetos podem ser executados concomitantemente com o conteúdo digital e estão disponibilizados como applets. De acordo com Oliveira (2004), applets são programas interativos, escritos em linguagem Java, que podem ser

\section{FÓRMULA MUNDY}

Diante da dificuldade dos discentes de localização e conversão de medidas usuais no ciclo trigonométrico, foi construída uma animação denominada Fórmula Mundy como parte integrante de uma videoaula sobre arcos e ângulos. Esta animação foi retomada ao longo das demais videoaulas sobre funções trigonométricas, por ser útil na construção de outros conceitos, como mostra a Figura1.

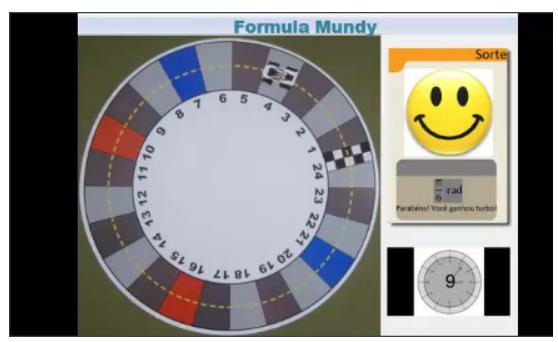

Figura 1 - Tela do jogo Fórmula Mundy durante a videoaula.

Este OA é uma animação que simula um jogo de tabuleiro inédito desenvolvido e aplicado como teste de validação para complementar a videoaula. Essa aplicação ocorreu em duas turmas do segundo ano do executados em qualquer browser ou outro aplicativo Java. Sendo assim o estudante pode estudar um conceito específico e depois visualizá-lo para tirar conclusões próprias e confrontar com a teoria, ou pode primeiro, visualizar/experimentar e fazer conjecturas, para somente depois estudar a teoria.

Ensino Médio de uma escola parceira do Programa Institucional de Bolsas de Iniciação à Docência (PIBID), durante a realização de uma oficina sobre funções trigonométricas. Esta atividade, com duração de duas aulas de 50 minutos cada, contou com a participação de 84 alunos, como realça a Figura 2.

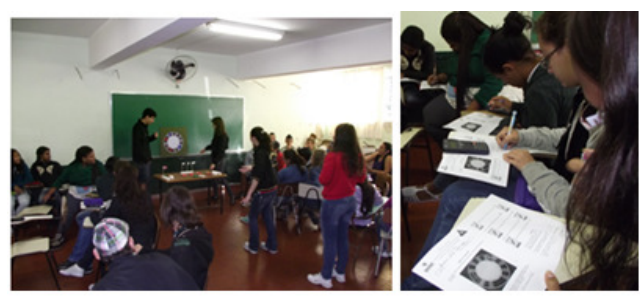

Figura 2 - Alunos durante a aplicação do Jogo Fórmula Mundy

Para a elaboração da atividade, foram criados: uma animação de corrida, cartas contendo valores de ângulos e um relógio virtual. Ainda, são apresentados desafios aos estudantes e um tempo para que ocorra a reflexão antes que se forneça a solução.

Para construir o cenário da corrida foi projetada uma pista em formato circular associada ao ciclo trigonométrico e dividida 
em 24 partes iguais, cada uma correspondendo a um ângulo de 15 graus. O carrinho se movimenta de acordo com as informações contidas nas cartas, que são valores de ângulos tanto em graus quanto em radianos. Além disso, as casas azuis e vermelhas representam bônus e penalidades, respectivamente, no jogo.

As cartas são de dois tipos, de sorte ou de azar dependendo do ângulo proposto. Além da informação do ângulo a ser percorrido as cartas apresentam frases motivadoras e frases de penalizações associadas a imagens que expressam a situação, como exibe a Figura 3.

\section{METODOLOGIA}

O OA desenvolvido incorpora conceitos e aplicações com o uso de animações oriundas da junção de diversos programas computacionais.

A edição das imagens da pista, do carrinho e das cartas foi realizada no Gimp. Este programa permite a criação de animações utilizando camadas, unindo as imagens dos carrinhos com a foto da pista proporcionando a movimentação do carro e criando seu movimento rotacional contínuo. Ainda, durante a animação, associada ao

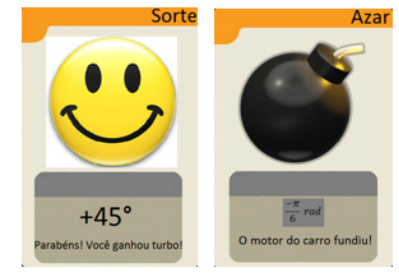

Figura 3 - Cartas do OA demonstrando a variação dos ângulos.

A partir da união dos elementos, temos a representação de uma corrida iniciando e terminado na linha de largada, após três voltas. O carrinho irá se movimentar de acordo com o valor que aparecer na carta da lateral, se for positivo, o carrinho anda no sentido anti-horário, se for negativo, ele se locomove no sentido horário. Todavia ele somente se movimentará quando o relógio zerar, dando o tempo necessário para o aluno realizar os cálculos e decidir para qual casa o carrinho deverá ir.

aparecimento das cartas, acontece a narração de situações e questionamentos que induzem o aluno a descobrir em qual posição o carrinho deverá se localizar mediante o ângulo correspondente. O relógio que marca o tempo dado ao aluno para pensar no desafio, como exibe a Figura 4, é uma animação criada com o auxílio do software GeoGebra. A escolha pautou-se pela característica do programa em reunir ferramentas de álgebra, geometria e cálculo, podendo ser explorado em diversas situações e conteúdos. 


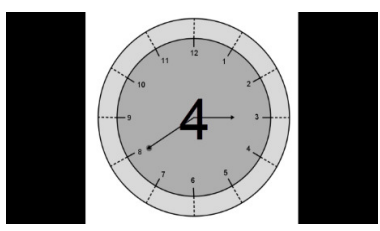

Figura 4 - Representação do tempo por meio do relógio

Para a edição dos vídeos foi utilizado o software proprietário Camtasia Studio e para a elaboração da narrativa foi usado o software proprietário TextAloud. A junção destes componentes originou no OA Fórmula Mundy.

A animação elaborada foi aplicada em uma turma composta por 20 alunos ingressantes em um curso de licenciatura em matemática, durante uma disciplina curricular denominada Fundamentos da Matemática Elementar. Foi desenvolvido um caderno de

\section{RESULTADOS E DISCUSSÃO}

O Gráfico 1 apresenta o resultado das respostas dos discentes quando indagados sobre as fontes de pesquisa e estudo utilizados. Observe que a fonte mais utilizada pelos discentes é a internet.

Confirmando-se assim, a crescente utilização das novas tecnologias de informação e comunicação, não somente para entretenimento, mas também como uma fonte de pesquisa e aprendizagem, principalmente aquela que propõe maior interação e rapidez, como vídeos. acompanhamento referente ao estudo das funções trigonométricas, além de um questionário inicial e outro final para coleta de dados. O caderno de acompanhamento continha questões referentes aos assuntos abordados durante as videoaulas apresentadas. Já os questionários possuíam perguntas sobre a frequência da utilização da internet como fonte de pesquisa, estudo, emprego e a avaliação de $\mathrm{OA}$ em sequências didáticas educativas.

Ao final desta aplicação os questionários iniciais e finais foram coletados para a avaliação da sequência desenvolvida. É importante ressaltar que em ambos os casos, os discentes responderam aos questionamentos anonimamente de forma a não comprometer a coleta de dados.

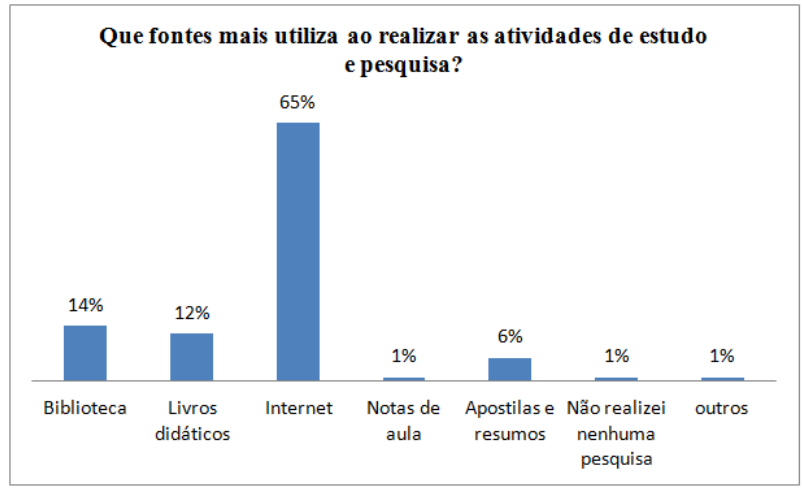

Gráfico 1 - Fontes de estudo e pesquisa citados pelos discentes.

A mudança no comportamento dos alunos em relação as suas fontes de pesquisa exige a produção e disponibilização de material didático com informações confiáveis, de acordo com pressupostos pedagógicos sólidos e com qualidade visual. 
A busca e análise do material online sobre conteúdos de matemática básica revela que os mesmos são apresentados de maneira simplificada com exercícios puramente mecânicos, definições, às vezes, incorretas, imagens e vídeos com má resolução. Há exceções, alguns repositórios e páginas online apresentam os temas matemáticos bem estruturados. Destacam-se as páginas Matemática Multimídia, Analyzemath, Portal do Professor e a Rede Interativa Virtual de Educação (RIVED). O projeto Matemática Multimídia apresenta, especificamente para o estudo de funções trigonométricas, vídeos, softwares e áudios em ótima qualidade, tanto pedagógico quanto visual. Por outro lado, o Analyzemath, o Portal do Professor e o RIVED contem propostas de representações gráficas interativas disponibilizando ao aprendiz a possibilidade de desenvolver conjecturas, testar e visualizar diversos conceitos matemáticos. Porém, nada foi encontrado sobre o estudo da localização no ciclo trigonométrico.

Cerca de $38 \%$ dos alunos participantes da pesquisa, apontaram que a maior dificuldade encontrada, durante seus anos escolares, está relacionada ao tema funções trigonométricas e a análise do ciclo A indagação sobre a consideração do conhecimento matemático dos aprendizes antes e após a aplicação do OA está representada no Gráfico 2. Observe que o conhecimento considerado regular, inicialmente cede lugar ao conhecimento trigonométrico. Enquanto $34 \%$ afirmam ter dificuldades na análise e construção de gráficos de funções reais. Além disso, cerca de $37 \%$ dos discentes declararam que o tema funções trigonométricas é estudado simplificadamente, de maneira rápida e restrita. Os resultados revelam a demanda por material didático digital tendo como foco o estudo de funções trigonométricas.

Com a utilização da animação, houve a possibilidade dos alunos assimilarem a ideia da conversão de unidades e da localização destas no ciclo trigonométrico, através do posicionamento do carrinho após uma determinada movimentação no ciclo. Assim, observou-se que os participantes mostraram interesse com o processo acompanhando o vídeo e demonstrando curiosidade com o AO.

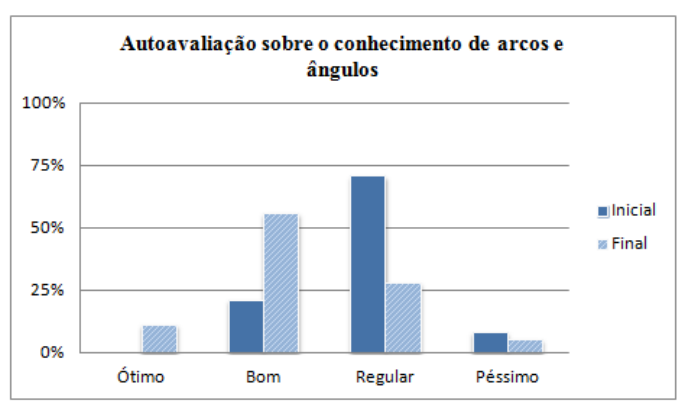

Gráfico 2 - Avaliação do conhecimento sobre arcos e ângulos antes e após a aplicação do OA.

considerado ótimo e bom após o estudo utilizando com o OA. Constatamos assim, a eficiência do $\mathrm{OA}$ na motivação para o aprendizado do tema em questão. Este fato pôde ser observado durante o acompanhamento, onde alguns discentes 
afirmaram ter assistido a videoaula por mais de uma vez.

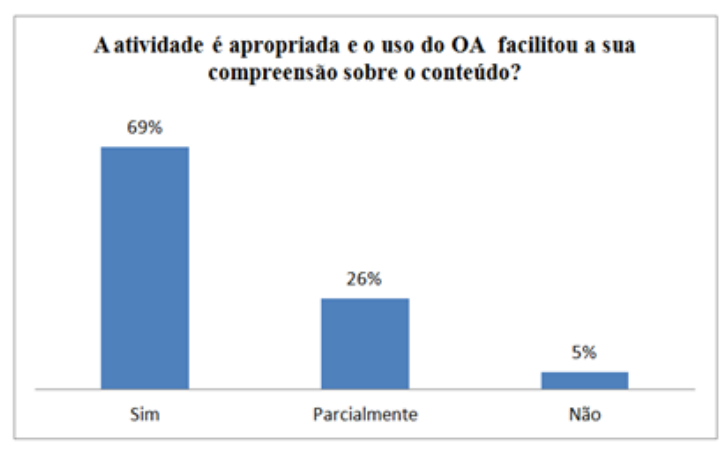

Gráfico 3 - Análise do OA durante o questionário final.

Somado ao interesse do conhecimento adquiro pelo aluno durante o processo, o questionário investigativo final propõe uma avaliação do OA aplicado, mostrado no Gráfico 3. Desta forma, foi possível verificar que houve uma maior facilidade de compreensão do tópico proposto mediante a utilização da animação. Ainda, de acordo com os resultados apresentados Gráfico 4, cerca de $80 \%$ dos participantes afirmaram que a motivação aumentou após utilizar o AO. Estes realçaram que utilizariam novamente este $\mathrm{OA}$ durante atividades em sala de aula como método alternativo e motivacional de ensino. A análise do desempenho dos sujeitos em questões especificas de localização no ciclo trigonométrico Gráfico 4, revela que houve de funções trigonométricas. $\mathrm{O}$ recurso tecnológico proporcionou a motivação necessária para o desenvolvimento e realização das atividades futuras sobre funções trigonométricas. um avanço no conhecimento, inclusive em questões que envolvem habilidades de localização e medida de arcos dadas em radianos.

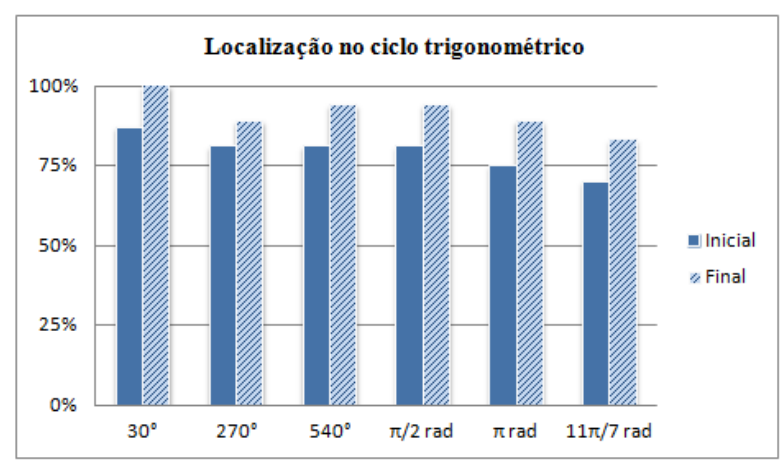

Gráfico 4: Desempenho dos discentes sobre questões especificas de localização no ciclo trigonométrico.

\section{CONSIDERAÇÕES FINAIS}

A tecnologia tornou-se uma grande aliada no meio educacional, principalmente no ensino de Matemática, pois permite a visualização, manipulação e construção de conceitos abstratos facilitando o processo de ensino-aprendizagem.

A animação do presente estudo contribuiu para a aprendizagem de $\operatorname{arcos} \mathrm{e}$ ângulos no ciclo trigonométrico, que é um conceito prévio para a aprendizagem

A OA inserida na videoaula é uma proposta de material didático que pode ser utilizado como complemento das atividades escolares, além de servir ao próprio professor em sala de aula. 
Como trabalhos futuros pretende-se desenvolver o jogo digital deste OA de forma a proporcionar uma maior interatividade.

\section{AGRADECIMENTOS:}

Agradecemos ao apoio do PIBID/CAPES e FAPEMIG, e em especial, agradecemos as discentes Elizandra Karla Odorico e Helen Maria Pedrosa de Oliveira, por suas contribuições a concepção do jogo Fórmula Mundy e durante a produção das videoaulas, respectivamente.

\section{REFERÊNCIAS BIBLIOGRÁFICAS}

BIZELLI, M. H. S. S.; FISCARELLI, S. H.; OLIVEIRA, L. A. A. Conteúdos digitais para o ensino de cálculo: aceitação, demandas e expectativas dos alunos. In: Encontro Iberoamericano de Educação, IV, 2009, Araraquara. Anais... Araraquara: EIDE, 2009. BRASIL. Parâmetros curriculares nacionais: matemática. Brasília: $\mathrm{MEC} / \mathrm{SEF}$, 1998.

CARDOSO, A.; SOUZA JUNIOR, J. C. Conteúdos didáticos digitais para aprendizagem de funções. SIMPÓSIO
BRASILEIRO DE INFORMÁTICA NA EDUCAÇÃO, XXII, Aracajú. Anais ... p.371-379, 2011.

ENGESTRÖM, Y. Activity theory and individual and social transformation. In: Engeström, Y. et al. Perspectives on activity theory. Cambridge: MIT Press, 1999.

LIMA, E. L. Exame de textos: Análise de livros de matemática para o ensino médio. Rio de Janeiro: Sociedade Brasileira de Matemática, 2001.

MAYER, R. Multimedia learning. New York: Cambridge Press, 2001.

OLIVEIRA, M. P. S. DE et al. Ferramenta para apoio ao ensino de física básica. SIMPÓSIO BRASILEIRO DE INFORMÁTICA NA EDUCAÇÃO, XV, Manaus. Anais ..., 2004.

\section{VERSUTI, A. C. Educação a distância: problematizando critérios de avaliação e qualidade em cursos on-line. Diferentes abordagens de EAD. Coleção Série Informática na Educação TV Educativa, 2004.}

